\section{Ensaio fotográfico}

* Recebido em 20.10.2018. Aprovado em: 13.12 .2018

** Professora Convidada da Unesp Araraquara, do Departamento de Antropologia. Email:

yara_schreiber@uol.com.br

*** Docente no curso de Arquitetura e Urbanismo da FIAM-FAAM Centro Universitário.

mdines@uol.com.b

\title{
Holi Festival - primavera, cor e semeadura na Índia/São Paulo*
}

Holi Festival - spring, color and seeding in India / São Paulo

Yara Schreiber Dines** e Milton Dines***

Resumo: Exposição fotográfica sobre o Holi Festival, em São Paulo, realizado pela comunidade hindu nesta cidade. É comemorado em abril, a cada ano, celebrando a chegada da primavera na Índia e a semeadura, com boa sorte.

Palavras-chaves: Festas populares, Alteridade, Identidade
Abstract: Photographic exhibition about the Holi Festival in São Paulo, held by the Hindu community in this city. It is celebrated in April each year, celebrating the arrival of spring in India and sowing with good luck.

Keywords: Alterity, Identity, Popular Holidays 


\section{Yara Schreiber Dines}

\section{Milton Dines}

\section{Ficha técnica}

TÍTULO: Holi Festival - primavera, cor e semeadura na Índia/São Paulo Holi Festival -

primavera, color y siembra en la Indi a/ São Paulo

Holi Festival - spring, color and

seeding in India / São Paulo

AUTORIA - Yara Schreiber Dines e Milton Dines

RESUMO - Exposição fotográfica sobre o Holi Festival, em São Paulo, realizado pela comunidade hindu nesta cidade. É comemorado em abril, a cada ano, celebrando a chegada da primavera na Índia e a semeadura, com boa sorte.

NÚMERO DE FOTOS, DIMENSÃO E PAPEL DE IMPRESSÃO - 08 fotos, $23,20 \times 35,10 \mathrm{~cm} ; 01$ fotos $23,20 \times 20 \mathrm{~cm}$; e 01 foto $23,20 \times 18 \mathrm{~cm}$ papel fotográfico.

ANO DE PRODUÇÃO - 2019

LOCAL DE PRODUÇÃO - São Paulo

PROJETO DE PESQUISA - Festa populares, Alteridade, Identidade INSTITUIÇÃO - USP
O Holi é uma festa hinduísta, a religião mais antiga da Índia. A celebração está fundamentada na lenda dos deuses Krishna e Radha. De acordo com a lenda, Krishna amava Radha, porém se sentia mal em virtude da diferença de cor de suas peles. Ele ouvindo sua mãe, pintou o rosto colorido para ficar da mesma cor que sua amada, no intuito que celebrassem o seu amor sem julgamentos.

$\mathrm{Na}$ Índia, o festival é realizado anualmente entre fevereiro e março, quando é o início da primavera, época de semeadura no campo. É uma das festas indianas mais populares, assemelhando-se ao nosso carnaval, por envolver música, dança e alegria.

São acesas fogueiras pelas ruas das cidades, sendo que este ritual representa a limpeza dos aspectos negativos do ano que passou. Após a limpeza cerimonial, em que os festeiros andam em círculos e fazem preces, em volta das fogueiras, estes passam a jogar pó colorido uns nos outros, se saudam, dizendo Happy Holi, brindando a festa e para trazer sorte. Cada cor simboliza um valor humano.

Na metrópole paulistana, a Indian Association realiza o Holi Festival no São Paulo Athletic Club, durante o início de abril, num domingo, na represa de Guarapiranga. Reúne famílias de imigrantes de jovens hindus e também entusiastas da cultura indiana, da capital, comemorando com intensidade, cor, vivacidade e envolvimento, a cada ano, a chegada da primavera e a "semeadura" da boa sorte do ano, que está despontando. O processo do ritual é semelhante ao que acontece na Índia, com o acendimento da fogueira. No decorrer do ritual, alguns casais dançam, homens e mulheres também, porém em grupos separados por gênero. Os festeiros mostram os laços com a terra, que deixaram para trás, mas está presente em cada um deles. 

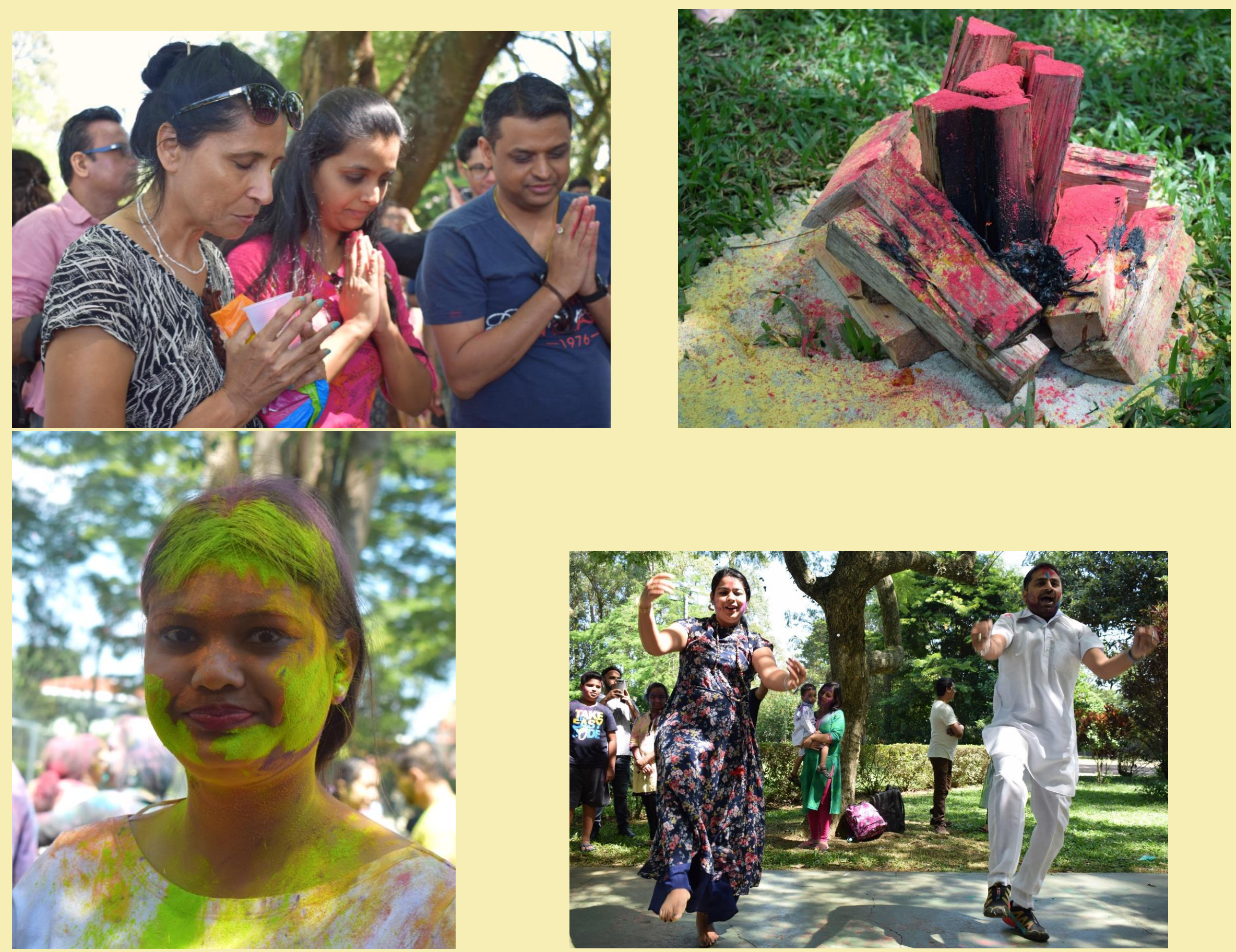

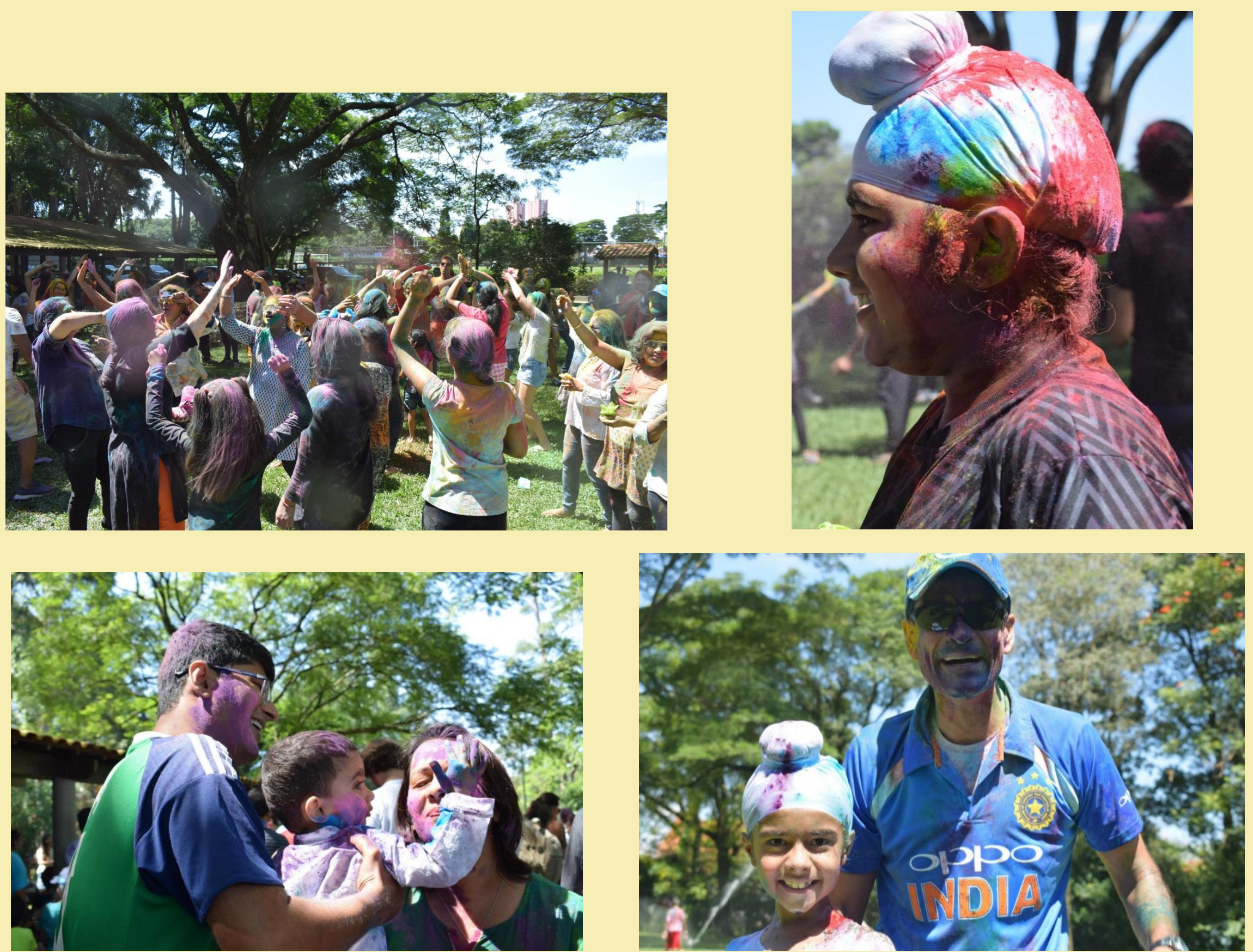